\title{
Effects of prolonged exercise training and exhaustive chasing training on the swimming performance of an endangered bream Megalobrama pellegrini
}

\author{
Xiu-Ming Li ${ }^{1,2}$, Xu Pang ${ }^{1}$, Hua Zheng ${ }^{2}$, Xiao-Jin $\mathrm{Li}^{2}$, Shi-Jian $\mathrm{Fu}^{2}$, \\ Yao-Guang Zhang ${ }^{1, *}$
}

\begin{abstract}
${ }^{1}$ Key Laboratory of Freshwater Fish Reproduction and Development (Education Ministry), Key Laboratory of Aquatic Science of Chongqing, School of Life Sciences, Southwest University, Chongqing 400715, PR China ${ }^{2}$ Laboratory of Evolutionary Physiology and Behavior, Chongqing Key Laboratory of Animal Biology, Chongqing Normal University, Chongqing 401331, PR China
\end{abstract}

\begin{abstract}
Swimming performance of fish is often improved following periods of moderate exercise training. To examine the effects of training regimes on swimming performance of juvenile bream Megalobrama pellegrini $(5.10 \pm 0.08 \mathrm{~g}$ ), fish were held in slow-flowing water (control), or subjected to exercise training at 1 body length (BL) s${ }^{-1}, 2 \mathrm{BL} \mathrm{s}^{-1}$ or $4 \mathrm{BL} \mathrm{s}^{-1}$, or were given exhaustive chasing training daily for $5 \mathrm{wk}$ at $25^{\circ} \mathrm{C}$. Aerobic swimming performance was assessed by measuring critical swimming speed $\left(U_{\text {crit }}\right)$. Maximum metabolic rate $(\mathrm{MMR})$, metabolic scope (MS), cost of transport (COT) and net cost of transport $\left(\mathrm{COT}_{\text {net }}\right.$ ) were assessed by measurement of oxygen consumption rates $\left(\mathrm{MO}_{2}\right)$. $U_{\text {crit }}$ was significantly higher in the $4 \mathrm{BL} \mathrm{s}^{-1}$ training group than in the controls. The value of $U_{\text {crit }}$ was $5 \%$ greater for the exhaustive training group compared with the control group, although exhaustive chasing training did not have a significant effect on $U_{\text {crit }}$. MMR and MS were not significantly different across treatments. $\mathrm{MO}_{2}$ and COT of fish in the 4 BL $\mathrm{s}^{-1}$ and exhaustive training groups were significantly lower than in the control group in the swimming speed range of approximately $36-60 \mathrm{~cm} \mathrm{~s}^{-1}$. This suggests that high-intensity prolonged exercise training and exhaustive chasing training have a positive influence on the swimming performance of juvenile $M$. pellegrini, which may be related to elevated anaerobic metabolism and improved swimming efficiency.
\end{abstract}

KEY WORDS: Aerobic exercise training - Anaerobic exercise training $\cdot$ Critical swimming speed · Megalobrama pellegrini

\section{INTRODUCTION}

Because fish can be prompted to swim against a water flow, they are ideal experimental animals for studies on the effects of exercise training (Davison 1997). The 2 main purposes of training research in fish are to improve the growth performance of fish and improve their survival rate once they are released into the wild (Jobling et al. 1993, Davison

${ }^{*}$ Corresponding author: zhangyg@swu.edu.cn
1997). Many changes, such as morphological and histological characteristics (Davison \& Goldspink 1977, Ibarz et al. 2011), flesh quality (Palstra \& Planas 2011, Rasmussen et al. 2011, Song et al. 2012), physiological function (Bagatto et al. 2001, Liu et al. 2009, Castro et al. 2011) and behavior characteristics (Totland et al. 1987, van der Meulen et al. 2006), have been found after training in fish which are related to the species that was used and the training regime (Davi-

() The authors 2017. Open Access under Creative Commons by Attribution Licence. Use, distribution and reproduction are unrestricted. Authors and original publication must be credited. 
son 1997). According to the demand for oxygen, the movement of fish can be divided into 2 types: aerobic and anaerobic. Therefore, exercise training protocols have been categorized as aerobic or anaerobic in fish (Pearson et al. 1990). So far, a large number of the studies investigating the effects of exercise training on fish species have studied cold-water salmonids (Davison \& Goldspink 1977, Davison 1997, Castro et al. 2011). However, there has been some recent work on warm-water teleosts that has increased our knowledge of exercise training in these fish species (Li et al. 2013, 2016).

Survival, growth and reproduction in fish depend heavily on swimming ability (Brett 1964, Blake 2004, Graham et al. 2004, Kieffer 2010, Cai et al. 2014). The swimming ability of fish is complex and varied, and it is often evaluated through many different indicators, such as critical swimming speed $\left(U_{\text {crit }}\right)$ and burst swimming speed (Colavecchia et al. 1998, Liu et al. 2009, Li et al. 2010a,b). $U_{\text {crit }}$ is not only a widely accepted evaluation index of aerobic swimming performance, but also reflects an anaerobic metabolism from approximately $60 \% U_{\text {crit }}$ onward in fish (Nelson et al. 1996, Gregory \& Wood 1998, Plaut 2001, Lee et al. 2003a,b). Many studies have found that $U_{\text {crit }}$ is heavily influenced by factors such as species (Pang et al. 2011), gastrointestinal fullness (Li et al. 2010a,b), temperature (Pang et al. 2011, 2013), dissolved oxygen level (Fu et al. 2011, Zhao et al. 2012) and exercise training (Liu et al. 2009, Fu et al. 2011, Zhao et al. 2012, He et al. 2013) in fish species. Some research has shown that exercise training has a positive effect on $U_{\text {crit }}$ in some fish, which is closely related to improvement of cardio-respiratory capacity (Farrell et al. 1991, Liu et al. 2009, Fu et al. 2011), increase in muscle fiber size, number of mitochondria (Davison \& Goldspink 1977, Davie et al. 1986) and/or enhanced activity of mitochondrial enzymes (Johnston \& Moon 1980). Improvement of swimming efficiency may also have a positive effect on $U_{\text {crit }}$ and is often evaluated through the cost of transport (COT) and net cost of transport $\left(\mathrm{COT}_{\text {net }}\right.$ ) in fish (Claireaux et al. 2006, Pang et al. 2013). Additionally, the optimal water velocity of exercise training for improvement of swimming performance has been found to be different for different fish species. Despite a few studies reporting no positive response of $U_{\text {crit }}$ to exercise training in some species (Farrell et al. 1991, Gruber \& Dickson 1997, Gallaugher et al. 2001), it is now widely accepted that optimal training water velocity is above $60 \% U_{\text {crit }}$ for improvement of $U_{\text {crit }}$ in many fish species (Liu et al. 2009, Zhao et al. 2012, He et al. 2013). Therefore, whether exercise training shows any effects on swimming performance has been suggested to be dependent on fish species, the type of training and environmental factors (Davison 1997, Pang et al. 2013).

In this study, we selected juvenile bream Megalobrama pellegrini, a warm-water cyprinid fish species, as the experimental model. $M$. pellegrini used to be found in the main streams and tributaries along the upper reaches of the Yangtze River of China (Duan et al. 2002). However, this species has become endangered due to the construction of dams and overfishing in the wild (Park et al. 2003, Li et al. 2007), and field surveys have revealed that populations of $M$. pellegrini have been decreasing rapidly across their original distribution (Li et al. 2007, Gao et al. 2010). Studies on reproductive biology and implementation of stock enhancement have contributed to the conservation of this endangered species (Wang et al. 2005, Li et al. 2007). Some studies have found that exercise training at a moderate water velocity can improve swimming ability and hence lead to better survival of released juvenile fish raised in hatcheries (Hoffnagle et al. 2006, Castro et al. 2011, Palstra \& Planas 2011). Thus, investigation on how exercise affects swimming performance of this species will provide practical information for the protection of this species. The objectives of this study were to (1) investigate whether prolonged exercise training improves swimming performance in juvenile M. pellegrini, and, if it does, to determine the optimal water velocity for exercise training; (2) examine whether exhaustive chasing training could improve swimming performance in juvenile $M$. pellegrini and serve as an alternative training protocol to sustained exercise training; and (3) determine whether improved swimming performance is related to improved swimming efficiency. To achieve these aims, we assessed aerobic swimming performance by measuring $U_{\text {crit, }}$ aerobic metabolic capacity by maximum metabolic rate (MMR) and metabolic scope (MS), and swimming efficiency by measuring oxygen consumption rates $\left(\mathrm{MO}_{2}\right), \mathrm{COT}$ and $\mathrm{COT}_{\text {net }}$ in juvenile $M$. pellegrini after prolonged exercise training and exhaustive chasing training.

\section{MATERIALS AND METHODS}

\section{Experimental fish and acclimation}

Juvenile Megalobrama pellegrini (Cypriniformes: Cyprinidae) were obtained from a local hatchery (Beibei, Chongqing, China) and kept in a cement 
pond system (approximately 1200 l) with fully aerated recirculating water at Southwest University for $4 \mathrm{wk}$ prior to the experiment. During this period, the temperature of the de-chlorinated tap water in the pond was maintained at $25.0 \pm 0.5^{\circ} \mathrm{C}$, and the oxygen level was kept above $7 \mathrm{mg} \mathrm{l}^{-1}$. The photoperiod was a $12 \mathrm{~h}$ light:12 $\mathrm{h}$ dark schedule, with the lights turned on and off at 08:00 and 20:00 $\mathrm{h}$, respectively. Fish were fed twice daily (09:00 and 19:00 h) to apparent satiation with commercial floating pellets (Tongwei; dietary composition: $41.2 \pm 0.9 \%$ protein, $8.5 \pm 0.5 \%$ lipid, $25.7 \pm 1.2 \%$ carbohydrate and $12.3 \pm$ $0.4 \%$ ash).

\section{Training protocol}

After 4 wk of acclimatization, 150 fish with a similar size $(5.10 \pm 0.08 \mathrm{~g}, 6.52 \pm 0.10 \mathrm{~cm})$ were slightly anesthetized (neutralized MS222, tricaine methanesulfonate, $50 \mathrm{mg} \mathrm{l}^{-1}$ ) and then transferred into a selfmade exercising system described by Li et al. (2016) for exercise training. Continuous water velocities in the experimental flume were achieved via the motors $(30 \mathrm{~W})$ with propeller. Different water velocities were produced by controlling the different voltages of transducer power. Fish were randomly divided into 5 groups of 30 individuals (control group, 1 body length $[\mathrm{BL}] \mathrm{s}^{-1}$ training group, $2 \mathrm{BL} \mathrm{s}^{-1}$ training group, $4 \mathrm{BL} \mathrm{s}^{-1}$ training group and exhaustive training group) that were placed in flumes $(140 \times 15 \times$ $20 \mathrm{~cm}, \mathrm{~L} \times \mathrm{W} \times \mathrm{D}$ ) with different water velocities within the exercising system. All 30 fish in each training group were trained as a unit.

The protocols of prolonged exercise training followed $\mathrm{Li}$ et al. (2013). Our pilot experiment found that a water velocity $>2 \mathrm{~cm} \mathrm{~s}^{-1}$ can guarantee the full water exchange which is the prerequisite of the present study, but a water velocity $>5 \mathrm{~cm} \mathrm{~s}^{-1}$ caused spontaneous swimming activities in juvenile $M$. pellegrini. Therefore, fish in the control group swam at an average water velocity of $3 \mathrm{~cm} \mathrm{~s}^{-1}$. The water velocity was beneficial for water exchange and did not lead to spontaneous swimming activities in juvenile M. pellegrini. The fish in the 3 prolonged training groups were forced to swim against 3 different water velocities: 1, 2 and $4 \mathrm{BL} \mathrm{s}^{-1}$ (approximately 7, 14 and $28 \mathrm{~cm}$ $\mathrm{s}^{-1}$, respectively), for a total of $18 \mathrm{~h} \mathrm{~d}^{-1}$. After prolonged training for $9 \mathrm{~h}$, the exercise was ceased and these fish were fed once to satiation at 09:00 $\mathrm{h}$ (or 19:00 h) with commercial floating pellets at a water velocity of $3 \mathrm{~cm} \mathrm{~s}^{-1}$. To reduce physiological stress, water velocity was gradually increased over $4 \mathrm{~d}$ until the desired water velocity was reached for the first round of training at the beginning of the experiment (Davison \& Goldspink 1978). Water velocities were adjusted every other week after the BL of the fish had been measured.

The protocols for exhaustive chasing training followed the methods of Liu et al. (2009). The 30 fish in the exhaustive training group were transferred from the flume into a circular container with a water velocity of approximately $65 \mathrm{~cm} \mathrm{~s}^{-1}$ (diameter $104 \mathrm{~cm}$ ) in the same time and chased with a hand net to an exhausted state for approximately $5 \mathrm{~min}$. During chasing, any lagging individuals were occasionally touched by the hand net. The exhausted fish were immediately returned to the flume (with an average water velocity of $3 \mathrm{~cm} \mathrm{~s}^{-1}$ ) when they lost their balance or did not respond to stimuli. Training was conducted once per day at 15:00 h.

The prolonged exercise training or exhaustive chasing training was carried out for $5 \mathrm{wk}$. The dissolved oxygen level was approximately $7 \mathrm{mg} \mathrm{l}^{-1}$, and the feeding regime and holding conditions for the experimental period were consistent with those of the acclimation period.

\section{Measurement of $\boldsymbol{U}_{\text {crit }}$ and swimming $\dot{\mathrm{M}} \mathrm{O}_{2}$}

$U_{\text {crit }}$ was measured by a Blakza-type swimming tunnel respirometer (total volume $3.5 l_{\text {i }}$ for details, see Li et al. 2010a, Pang et al. 2011). Eight fish from each group were individually transferred into the swim tunnel after $24 \mathrm{~h}$ of fasting and allowed to recover for $6 \mathrm{~h}$ at a water speed of $6 \mathrm{~cm} \mathrm{~s}^{-1}$ (Peng et al. 2014). Fish swam downstream of the propeller in a swimming chamber with a $19.9 \mathrm{~cm}^{2}$ cross-sectional area. Water velocity was increased by $6 \mathrm{~cm} \mathrm{~s}^{-1}$ increments every 20 min until fish were fatigued. Fatigue was defined as failure to move away from the rear honeycomb screen of the swimming chamber for $20 \mathrm{~s}$ (Lee et al. 2003a,b). Water temperature in the swimming chamber was controlled within $\pm 0.2^{\circ} \mathrm{C}$ using a water bath connected to a stainless-steel heat exchanger. $U_{\text {crit }}$ was calculated for individual fish using Brett's equation (Brett 1964):

$$
U_{\text {crit }}=v+(\mathrm{t} / \mathrm{T}) \Delta v
$$

where $v$ is the highest speed at which the fish swam for the full time period $\left(\mathrm{cm} \mathrm{s}^{-1}\right), \Delta v$ is the velocity increment $\left(6 \mathrm{~cm} \mathrm{~s}^{-1}\right), \mathrm{T}$ is the constant period of swimming per speed $(20 \mathrm{~min})$, and $\mathrm{t}$ is the time that the fish swam at the final speed (min). $U_{\text {crit }}$ was not corrected for the solid blocking effect because the cross- 
sectional area of the fish did not exceed $10 \%$ of the area of the swimming chamber. After the measurement of $U_{\text {crit, }}$ fish were taken out of the swimming chamber and euthanized with an overdose of MS222. Measurements of body mass and BL were taken to the nearest $0.1 \mathrm{~g}$ and $0.1 \mathrm{~cm}$.

$\dot{\mathrm{MO}}{ }_{2}$ values were measured during each $U_{\text {crit }}$ test as a function of swimming speed. In open mode, the respirometer was supplied with fully aerated and thermoregulated water that circulated in a reservoir tank at an approximate flow rate of $500 \mathrm{ml} \mathrm{min}^{-1}$. In closed mode, a small fraction of the water from the sealed respirometer was siphoned past the probe of an oximeter (HQ30, Hach) in a cuvette thermoregulated with a water bath. Water oxygen concentration $\left(\mathrm{mg} \mathrm{l}^{-1}\right)$ was recorded once every $2 \mathrm{~min}$. The standardized $\mathrm{MO}_{2}$ of an individual swimming fish was calculated from the depletion of oxygen according to the following equation ( $\mathrm{Li}$ et al. 2010b):

$$
\dot{\mathrm{MO}_{2}}=60 \text { slope } \mathrm{VOL} / \mathrm{m}
$$

where slope is the decrease in the water's dissolved oxygen content per minute. The slope was obtained with linear regressions between time ( $\mathrm{min}$ ) and the water's dissolved oxygen content $\left(\mathrm{mg} \mathrm{O}_{2} \mathrm{l}^{-1}\right.$ ). Only slopes with $\mathrm{r}^{2}>0.95$ were considered in the analysis. VOL is the total volume of the respirometer (3.5 l) minus the volume of the fish, and $m$ is the body mass $(\mathrm{kg})$ of the fish. The water oxygen content in the respirometer was never allowed to fall below $85 \%$ oxygen saturation (Claireaux et al. 2006).

For the individual fish swimming trials, the relationship between the swimming speed $\left(U, \mathrm{~cm} \mathrm{~s}^{-1}\right)$ and swimming $\mathrm{MO}_{2}\left(\mathrm{mg} \mathrm{kg}^{-1} \mathrm{~h}^{-1}\right)$ was described with the following equation (Webb 1975):

$$
\dot{\mathrm{MO}} 2=\alpha \mathrm{e}^{\beta U}
$$

where $\alpha$ and $\beta$ are constants, and e is base of the natural logarithm. RMR (resting metabolic rate; mg $\mathrm{kg}^{-1} \mathrm{~h}^{-1}$ ) was determined by extrapolation of Eq. (3) to a swimming speed of $0 \mathrm{~cm} \mathrm{~s}^{-1}$ (i.e. the $U$ ) (Priede 1985). The maximum $\dot{M O}_{2}$ was used as the value for MMR $\left(\mathrm{mg} \mathrm{kg}^{-1} \mathrm{~h}^{-1}\right)$ during the $U_{\text {crit }}$ test. MS was calculated by subtracting RMR from MMR.

$\mathrm{COT}$ and $\mathrm{COT}_{\text {net }}$ were calculated according to the following equations (Claireaux et al. 2006):

$$
\begin{aligned}
\mathrm{COT} & =\dot{\mathrm{MO}_{2}} \times \mathrm{OE} / \mathrm{V} \\
\mathrm{COT}_{\text {net }} & =\mathrm{MO}_{2 \text { net }} \times \mathrm{OE} / \mathrm{V}
\end{aligned}
$$

where $\dot{\mathrm{MO}}_{2}\left(\mathrm{mg} \mathrm{O}_{2} \mathrm{~kg}^{-1} \mathrm{~h}^{-1}\right)$ is the oxygen consumption rate of an individual swimming fish at a given water velocity. $\mathrm{MO}_{2 \text { net }}\left(\mathrm{mg} \mathrm{O} \mathrm{O}_{2} \mathrm{~kg}^{-1} \mathrm{~h}^{-1}\right.$ ) was calculated by subtracting the corresponding RMR from all $\dot{\mathrm{MO}}_{2}$ measurements. OE is an oxycalorific equivalent of $13.54 \mathrm{~J}\left(\mathrm{mg} \mathrm{O}_{2}\right)^{-1}$, and $v\left(\mathrm{~m} \mathrm{~h}^{-1}\right)$ is the corresponding water velocity converted from $\mathrm{cm} \mathrm{s}^{-1}$.

\section{Data analysis and statistics}

SPSS 17.0 software was used for data analysis. The effects of prolonged exercise training (among different speeds: control, 1, 2 and $4 \mathrm{BL} \mathrm{s}^{-1}$ ) on body mass, $\mathrm{BL}, U_{\text {crit }}, \mathrm{RMR}, \mathrm{MMR}$ and MS were determined using 1 -way ANOVA. ANOVA was followed by a least significant difference multiple-comparison test if it was necessary to determine the difference between the values of the different prolonged training groups. The effects of exhaustive chasing training (between control and treatment groups) on body mass, BL, $U_{\text {crit, }}$ RMR, MMR and MS were assessed using a $t$-test. The exponential function Eq. (3) translated to the linear equation $\dot{\mathrm{MO}}_{2}=\ln \alpha+\beta U$ via a double ln-transformation. The effects of swimming speed $(U)$ and exercise training (prolonged training at a given speed vs. control or exhaustive training vs. control) on swimming $\dot{\mathrm{MO}}_{2}$ were determined using ANCOVA with $U$ values as covariates (see Fig. 1). Thus the effect of treatment (training) was the difference in intercept, and the effect of interaction was the difference in slope. The effects of swimming speed and exercise training on COT and $\mathrm{COT}_{\text {net }}$ were assessed using 2 -way ANOVA. ANOVA was followed by a $t$-test if a statistical evaluation of a difference between the values was shown between the control and trained groups at the same swimming speed. A p-value $<0.05$ was considered to be statistically significant, and all values are presented as mean $\pm \mathrm{SE}$.

\section{RESULTS}

$$
U_{\text {crit }}
$$

Fish in the $4 \mathrm{BL} \mathrm{s}^{-1}$ training group showed a significantly higher $U_{\text {crit }}$ compared to the control group ( $\mathrm{p}<$ $0.05)$, whereas there were no significant differences in $U_{\text {crit }}$ among the $1 \mathrm{BL} \mathrm{s}^{-1}, 2 \mathrm{BL} \mathrm{s}^{-1}$, exhaustive training and control groups (Table 1).

\section{RMR, MMR and MS}

There were no significant differences in RMR, MMR and MS among all of the trained and control groups (Table 1). 


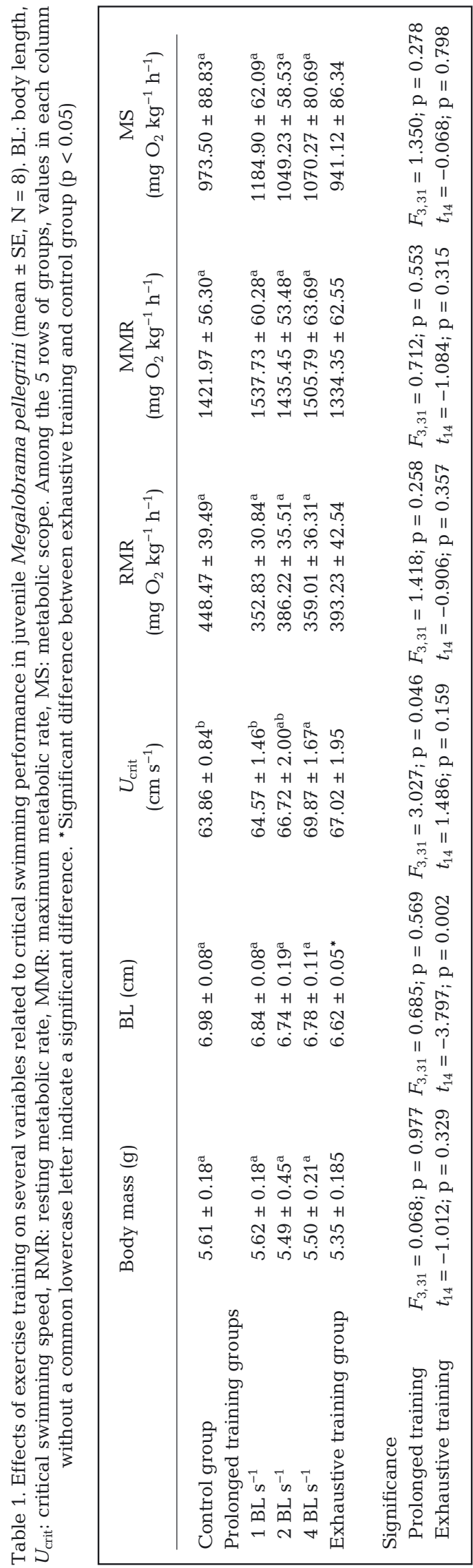

\section{Swimming $\dot{\mathrm{MO}}_{2}$}

Training and swimming speed had significant effects on $\dot{\mathrm{MO}}_{2}$ during the $U_{\text {crit }}$ test for all of the training groups $(\mathrm{p}=0.001, \mathrm{p}=0.002$ or $\mathrm{p}<0.001)$ (Table 2). $\quad \mathrm{MO}_{2}$ significantly increased with an increase in swimming speed for all training and control groups (Fig. 1). The $\mathrm{MO}_{2}$ values of fish in the $4 \mathrm{BL}$ $\mathrm{s}^{-1}$ training group were significantly lower compared to fish in the control group for swimming speeds of $24,36,42,48,54$ and $60 \mathrm{~cm} \mathrm{~s}^{-1}$ ( $\mathrm{p}<0.05$; Fig. 1). $\mathrm{MO}_{2}$ values of fish in the exhaustive training group were significantly lower than the control group at swimming speeds of $36,42,48$ and $60 \mathrm{~cm} \mathrm{~s}^{-1}(\mathrm{p}<0.05$; Fig. 1).

\section{COT}

Training and swimming speed had significant effects on COT during the $U_{\text {crit }}$ test for all training groups $(p=0.002$ or $p<0.001)$ (Table 2$)$. COT significantly decreased and then reached a plateau with an increase in the swimming speed for all training and control groups (Fig. 2). The COT values of fish in the $4 \mathrm{BL} \mathrm{s}^{-1}$ training group were significantly lower compared to the control group at swimming speeds of $24,36,42,48,54$ and $60 \mathrm{~cm} \mathrm{~s}^{-1}$ ( $\mathrm{p}<0.05$; Fig. 2). COT values of fish in the exhaustive training group were significantly lower than the control group at swimming speeds of $36,42,48$ and $60 \mathrm{~cm} \mathrm{~s}^{-1}(\mathrm{p}<$ 0.05; Fig. 2).

\section{$\mathrm{COT}_{\text {net }}$}

Training did not have a significant effect on $\mathrm{COT}_{\text {net }}$ in the $1 \mathrm{BL} \mathrm{s}^{-1}$ and $2 \mathrm{BL} \mathrm{s}^{-1}$ training groups, whereas training had significant effects on $\mathrm{COT}_{\text {net }}$ during the $U_{\text {crit }}$ test for the $4 \mathrm{BL} \mathrm{s}^{-1}$ and exhaustive training groups $(p=0.002$ or $p=0.008)$ (Table 2). Swimming speed had significant effects on $\mathrm{COT}_{\text {net }}$ during the $U_{\text {crit }}$ test for all training groups $(\mathrm{p}<0.001)$ (Table 2$)$. $\mathrm{COT}_{\text {net }}$ significantly increased with an increase in the swimming speed for all training and control groups (Fig. 3). $\mathrm{COT}_{\text {net }}$ in the exhaustive training group was significantly lower compared to the control group at a swimming speed of $12 \mathrm{~cm} \mathrm{~s}^{-1}(\mathrm{p}<0.05)$, whereas $\mathrm{COT}_{\text {net }}$ in all 3 prolonged training groups had no significant difference compared the control group at any given swimming speed (Fig. 3). 
Table 2. Effects of exercise training and swimming speed on oxygen consumption rate $\left.(\dot{\mathrm{MO}})_{2}\right)$, cost of transport (COT) and net cost of transport $\left(\mathrm{COT}_{n e t}\right.$ ) in juvenile Megalobrama pellegrini (mean $\pm \mathrm{SE}$ ). $\mathrm{MO}_{2}$ based on $\mathrm{ANCOVA}_{i} \mathrm{COT}_{\text {and }} \mathrm{COT}_{\text {net }}$ based on 2-way ANOVA. BL: body length. ${ }^{*} \mathrm{p}<0.05$

\begin{tabular}{|c|c|c|c|c|}
\hline Training group & & $\dot{\mathrm{MO}_{2}}$ & $\mathrm{COT}$ & $\mathrm{COT}_{\text {net }}$ \\
\hline $1 \mathrm{BL} \mathrm{s}^{-1}$ & $\begin{array}{l}\text { Training effect } \\
\text { Swimming speed effect } \\
\text { Interaction effect }\end{array}$ & $\begin{array}{l}F_{1,151}=11.675 \\
\mathrm{p}=0.001^{*} \\
F_{1,151}=611.077 \\
\mathrm{p}<0.001^{*} \\
F_{1,150}=5.411 \\
\mathrm{p}=0.021^{*}\end{array}$ & $\begin{array}{l}F_{1,133}=10.491 \\
\mathrm{p}=0.002^{*} \\
F_{10,133}=19.497 \\
\mathrm{p}<0.001^{*} \\
F_{9,133}=1.607 \\
\mathrm{p}=0.119\end{array}$ & $\begin{array}{l}F_{1,133}=0.920 \\
\mathrm{p}=0.339 \\
F_{10,133}=18.409 \\
\mathrm{p}<0.001^{*} \\
F_{9,133}=1.018 \\
\mathrm{p}=0.429\end{array}$ \\
\hline $2 \mathrm{BL} \mathrm{s}^{-1}$ & $\begin{array}{l}\text { Training effect } \\
\text { Swimming speed effect } \\
\text { Interaction effect }\end{array}$ & $\begin{array}{l}F_{1,153}=9.915 \\
\mathrm{p}=0.002^{*} \\
F_{1,153}=572.852 \\
\mathrm{p}<0.001^{*} \\
F_{1,152}=0.266 \\
\mathrm{p}=0.607\end{array}$ & $\begin{array}{l}F_{1,134}=8.303 \\
\mathrm{p}=0.005^{*} \\
F_{11,134}=22.238 \\
\mathrm{p}<0.001^{*} \\
F_{9,134}=0.521 \\
\mathrm{p}=0.858\end{array}$ & $\begin{array}{l}F_{1,134}=0.450 \\
\mathrm{p}=0.503 \\
F_{11,134}=11.434 \\
\mathrm{p}<0.001^{*} \\
F_{9,134}=0.360 \\
\mathrm{p}=0.952\end{array}$ \\
\hline $4 \mathrm{BL} \mathrm{s}^{-1}$ & $\begin{array}{l}\text { Training effect } \\
\text { Swimming speed effect } \\
\text { Interaction effect }\end{array}$ & $\begin{array}{l}F_{1,158}=33.104 \\
\mathrm{p}<0.001^{*} \\
F_{1,158}=562.517 \\
\mathrm{p}<0.001^{*} \\
F_{1,157}=1.015 \\
\mathrm{p}=0.315\end{array}$ & $\begin{array}{l}F_{1,139}=26.671 \\
\mathrm{p}<0.001^{*} \\
F_{11,139}=21.536 \\
\mathrm{p}<0.001^{*} \\
F_{9,139}=0.577 \\
\mathrm{p}=0.814\end{array}$ & $\begin{array}{l}F_{1,139}=7.154 \\
\mathrm{p}=0.008^{*} \\
F_{11,139}=14.134 \\
\mathrm{p}<0.001^{*} \\
F_{9,139}=0.853 \\
\mathrm{p}=0.569\end{array}$ \\
\hline Exhaustive & $\begin{array}{l}\text { Training effect } \\
\text { Swimming speed effect } \\
\text { Interaction effect }\end{array}$ & $\begin{array}{l}F_{1,153}=20.601 \\
\mathrm{p}<0.001^{*} \\
F_{1,153}=459.370 \\
\mathrm{p}<0.001^{*} \\
F_{1,152}=0.779 \\
\mathrm{p}=0.379\end{array}$ & $\begin{array}{l}F_{1,134}=15.584 \\
\mathrm{p}<0.001^{*} \\
F_{11,134}=18.845 \\
\mathrm{p}<0.001^{*} \\
F_{9,134}=0.504 \\
\mathrm{p}=0.870\end{array}$ & $\begin{array}{l}F_{1,134}=10.315 \\
\mathrm{p}=0.002^{*} \\
F_{11,134}=12.090 \\
\mathrm{p}<0.001^{*} \\
F_{9,134}=0.890 \\
\mathrm{p}=0.536\end{array}$ \\
\hline
\end{tabular}
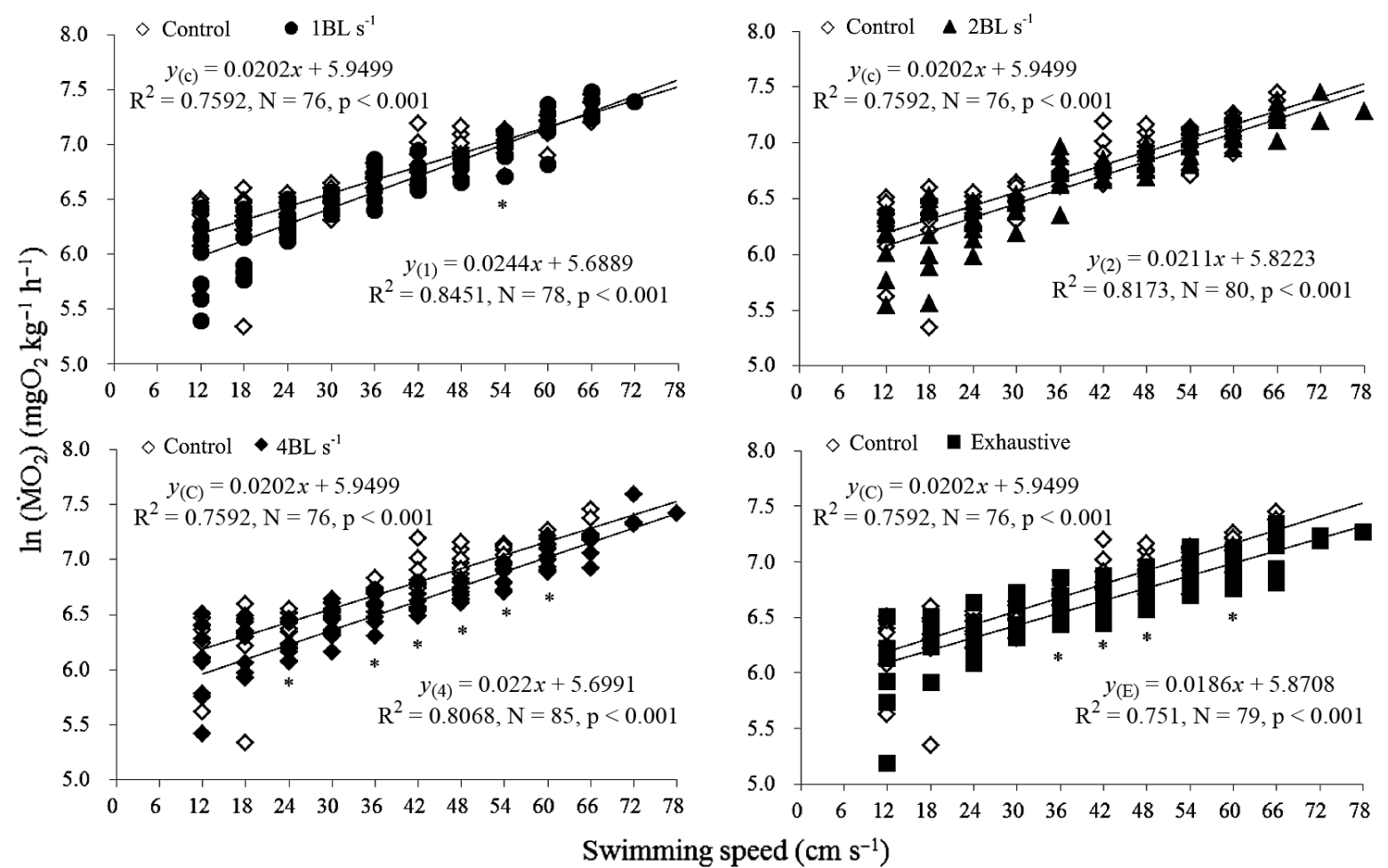

Fig. 1. Oxygen consumption rate $\left(\mathrm{MO}_{2}\right)$ vs. swimming speed curves for juvenile Megalobrama pellegrini for different training regimes vs. the control group: 1 body length (BL) s${ }^{-1}, 2 \mathrm{BL} \mathrm{s}^{-1}, 4 \mathrm{BL} \mathrm{s}^{-1}$, and exhaustive training. *Significant difference between training and control group under the same swimming speed $(\mathrm{p}<0.05)$ 

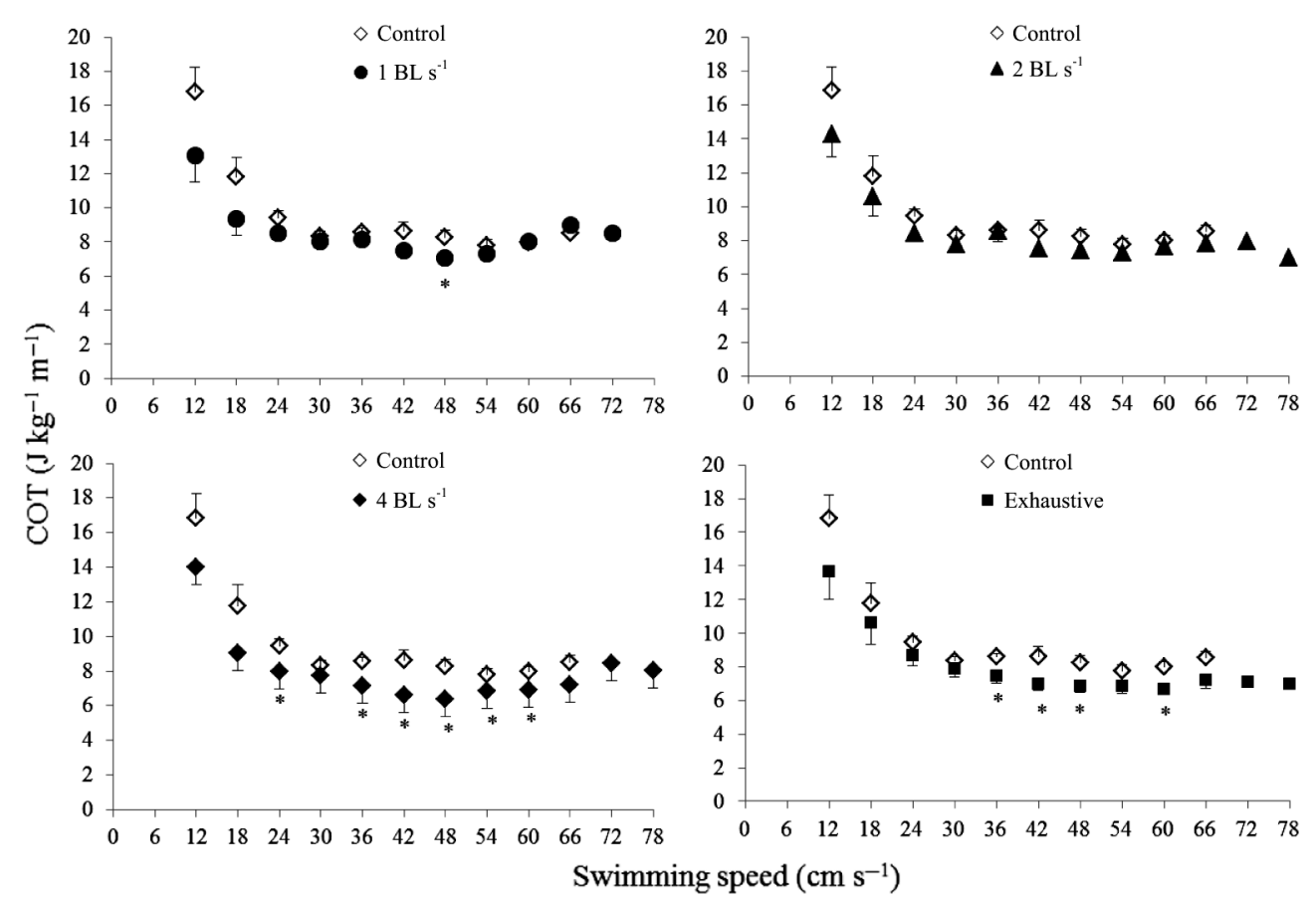

Fig. 2. Effects of swimming speed on cost of transport (COT) of juvenile Megalobrama pellegrini for different training regimes vs. the control group: 1 body length (BL) $\mathrm{s}^{-1}, 2 \mathrm{BL} \mathrm{s}^{-1}, 4 \mathrm{BL} \mathrm{s}^{-1}$, and exhaustive training. ${ }^{*}$ Significant difference between training and control group under the same swimming speed $(\mathrm{p}<0.05)$.

Data are mean $\pm \mathrm{SE}$
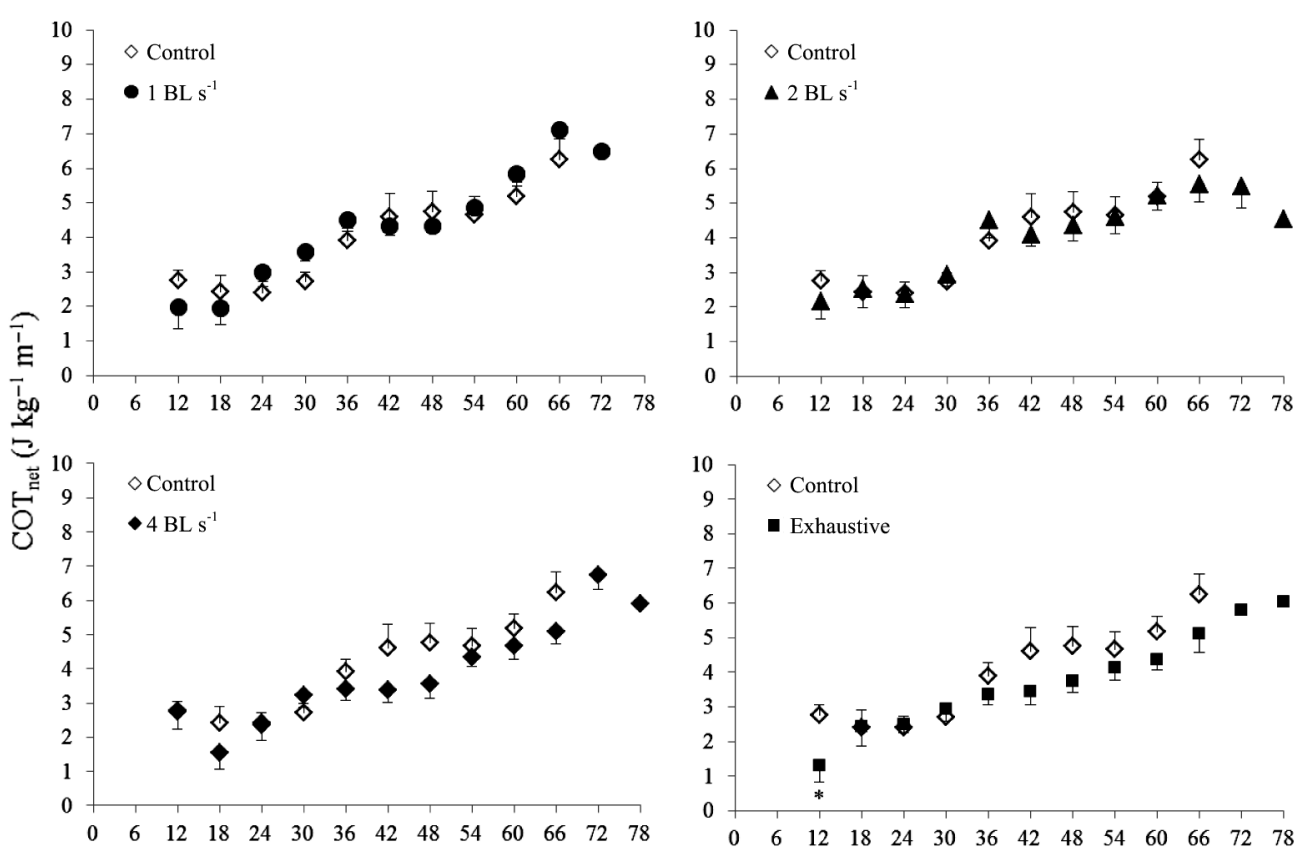

Swimming speed $\left(\mathrm{cm} \mathrm{s}^{-1}\right)$

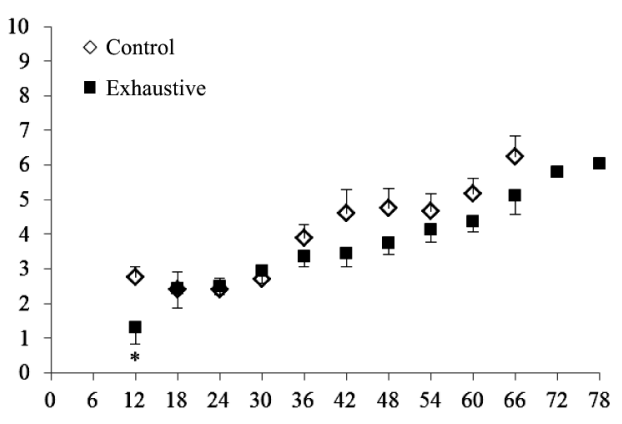

$\begin{array}{llllllllllllll}0 & 6 & 12 & 18 & 24 & 30 & 36 & 42 & 48 & 54 & 60 & 66 & 72 & 78\end{array}$
Fig. 3. Effects of swimming speed on net cost of transport $\left(\mathrm{COT}_{\text {net }}\right)$ of juvenile Megalobrama pellegrini for different training regimes vs. the control group: 1 body length (BL) $\mathrm{s}^{-1}, 2 \mathrm{BL} \mathrm{s} \mathrm{s}^{-1}, 4 \mathrm{BL} \mathrm{s} \mathrm{s}^{-1}$, and exhaustive training. *Significant difference between training and control group under the same swimming speed $(p<0.05)$.

Data are mean $\pm \mathrm{SE}$

\section{DISCUSSION}

The objective of this study was to investigate the effects of different training regimes on swimming performance and the possible underlying physiological mechanisms in juvenile Megalobrama pellegrini.
This study showed that prolonged exercise training at a higher water velocity or exhaustive chasing training increased $U_{\text {crit }}$ in this fish species, which was partly due to enhanced anaerobic metabolism and increased swimming efficiency compared to controls. 


\section{Effect on swimming performance}

$U_{\text {crit }}$ was not significantly different among the control and 1 and $2 \mathrm{BL} \mathrm{s}^{-1}$ groups. $U_{\text {crit }}$ in the $4 \mathrm{BL} \mathrm{s}^{-1}$ group increased significantly (Table 1). These results suggest that the intensity of training had a significant effect on $U_{\text {crit }}$ and that high-intensity swimming (4 $\mathrm{BL} \mathrm{s}{ }^{-1}$ ) resulted in an improvement in swimming performance. Improved $U_{\text {crit }}$ values have also been found in other trained fish species, such as the common carp Cyprinus carpio subjected to exercise training at $60 \% U_{\text {crit }}$ for $28 \mathrm{~d}$ (He et al. 2013), qingbo Spinibarbus sinensis subjected to exercise at $60 \% U_{\text {crit, }} 6 \mathrm{~h} \mathrm{~d}^{-1}$ for $14 \mathrm{~d}$ (Zhao et al. 2012) and striped bass Morone saxatilis subjected to exercise training at $1.2-2.4 \mathrm{BL} \mathrm{s}^{-1}$ for $60 \mathrm{~d}$ (Young \& Cech 1993). However, $U_{\text {crit }}$ values in trained leopard shark Triakis semifasciata (approximately $0.7 \mathrm{BL} \mathrm{s}^{-1}$ for $6 \mathrm{wk}$ ) and chinook salmon Oncorhynchus tshawytscha ( $U_{\text {crit }}$ swim test on alternate days for $4 \mathrm{mo}$ ) showed no significant differences compared to untrained fish (Gruber \& Dickson 1997, Gallaugher et al. 2001). The different effects of prolonged exercise training on the $U_{\text {crit }}$ of fish species may be related to the differences in the fish species that are chosen and the intensity and duration of training that were set (Liu et al. 2009, Zhao et al. 2012, Pang et al. 2013).

Red muscle fibers power aerobic exercise using aerobic metabolic pathways, and white muscle fibers utilize anaerobic metabolism and are recruited for anaerobic exercise in fish species. Therefore, many researchers generally believe that aerobic exercise training will help improve aerobic swimming performance, whereas anaerobic exercise training is helpful to improve anaerobic locomotor capacity in fish species (Davison 1997). Most of the previous studies examining the effects of exercise training on the $U_{\text {crit }}$ of fish have used aerobic rather than anaerobic exercise training (Young \& Cech 1993, Gruber \& Dickson 1997, Gallaugher et al. 2001, Fu et al. 2011, He et al. 2013, Zhao et al. 2012). However, some studies found that anaerobic exercise training has a significant effect on the $U_{\text {crit }}$ of fish species. For example, anaerobic exercise training (exhaustive chasing training daily for $14 \mathrm{~d}$ ) resulted in significant increases in $U_{\text {crit }}$ at $15^{\circ} \mathrm{C}$ in juvenile qingbo (Pang et al. 2013). Similar results were also documented in juvenile darkbarbel catfish Peltebagrus vachelli and southern catfish Silurus meridionalis (Liu et al. 2009, Li et al. 2010a,b). In the present study, exhaustive chasing training did not have a significant effect on $U_{\text {crit, }}$ but did lead to a $5 \%$ increase in the $U_{\text {crit }}$ of juvenile $M$. pellegrini compared to the untrained fish (Table 1). These results suggest that anaerobic exercise training might have a positive effect on the improvement of critical swimming capacity in juvenile $M$. pellegrini.

The experimental fish were obtained from one of the local artificial hatcheries which provide juvenile fish for fishery enhancement in the Three Gorges Reservoir. The experimental fish used in the present study as well as those released in the field usually show poorer swimming performance compared to their wild conspecifics because of parental effects, i.e. many generations being grown in captivity. Therefore, improvement in critical swimming capacity may improve food-capture and predator-avoidance capability in juvenile $M$. pellegrini after prolonged exercise training at a higher water velocity and exhaustive chasing training (Fu 2015). It may be beneficial to the survival rate after releasing this fish species into the wild.

\section{Effect on swimming efficiency}

To explore the mechanism of the effect of exercise training on the swimming performance in fish species, fish morphology, physiology, biochemistry, molecular biology etc. have been extensively studied (Johnston \& Moon 1980, Martin \& Johnston 2005, 2006, Fu et al. 2011, He et al. 2013). Some studies have found that the improvement of $U_{\text {crit }}$ was accompanied by the enhancement of aerobic metabolic capacity in trained fish (Liu et al. 2009, Li et al. 2010b). In the present study, prolonged exercise and exhaustive chasing training did not have significant effects on MMR and MS in juvenile $M$. pellegrini (Table 1). This suggests that neither training regime had any effect on aerobic metabolic capacity and that improvement of $U_{\text {crit }}$ may not be attributed to changes in the aerobic metabolic capacity in juvenile $M$. pellegrini subjected to highintensity prolonged exercise training $\left(4 \mathrm{BL} \mathrm{s}^{-1}\right.$ training) and exhaustive chasing training. This finding was similar to results previously documented for trained southern catfish and common carp (Li et al. 2010a, He et al. 2013).

Many studies have found that fish resort to anaerobic metabolism when swimming speed approaches approximately $60 \% U_{\text {crit }}$ or higher (Nelson et al. 1996, Lee et al. 2003a,b, Zhu et al. 2010). Therefore, the improved $U_{\text {crit }}$ in trained fish species might be due to an improvement in anaerobic metabolic capacity (He et 
al. 2013). In our study, the fish with $4 \mathrm{BL} \mathrm{s}^{-1}$ training and with exhaustive training showed a significantly lower $\mathrm{MO}_{2}$ at relatively high swimming speeds of $42-60 \mathrm{~cm} \mathrm{~s}^{-1}\left(>60 \% U_{\text {crit }}\right)$ when anaerobic metabolism was recruited during the measurement of $U_{\text {crit, }}$ which suggests that the trained fish may engage in more anaerobic metabolism at those speeds. This result may be a reason for the improvement in swimming performance in trained $M$. pellegrini. Furthermore, $4 \mathrm{BL} \mathrm{s}^{-1}$ training and exhaustive training had a significant effect on COT and $\mathrm{COT}_{\text {net }}$ of $M$. pellegrini (Table 2). Fish in the $4 \mathrm{BL} \mathrm{s}^{-1}$ and exhaustive training groups showed a significantly lower COT at a relatively low swimming speed of 24 and/or $36 \mathrm{~cm} \mathrm{~s}^{-1}$ $\left(<60 \% U_{\text {crit }}\right)$ (Fig. 2), suggesting that the increased swimming capacity may also result from improved swimming efficiency in juvenile $M$. pellegrini after training. A study of Atlantic salmon Salmo salar also found that continuous training at $0.8 \mathrm{BL} \mathrm{s}^{-1}$ for $6 \mathrm{wk}$ resulted in more efficient swimming at the highest swimming speed (1.6 BL s${ }^{-1}$ ) (Castro et al. 2011).

\section{CONCLUSIONS}

The effect of exercise training on swimming performance was closely related to the intensity and type of training in juvenile Megalobrama pellegrini. Prolonged exercise training at water velocities of 1 or $2 \mathrm{BL} \mathrm{s}^{-1}$ had no effect on swimming performance. However, increased $U_{\text {crit }}$ was found in the fish after undergoing aerobic exercise training at a higher water velocity $\left(4 \mathrm{BL} \mathrm{s}^{-1}\right)$. Anaerobic exercise training (exhaustive chasing) also resulted in a $5 \%$ increase in $U_{\text {crit }}$ compared to the control group. This enhancement may be related to an improvement in anaerobic metabolism and/or swimming efficiency in this bream, which may be beneficial to the survival rate after release into the wild. Further research is needed to determine swimming performance and survival rates in the field after undergoing training and detraining to provide more practical information for the protection of this fish species.

Acknowledgements. This study was funded by the National Natural Science Foundation of China (NSFC 31302160, 31670418), the 111 Project (B14037), the China Postdoctoral Science Foundation (2014M562271), the Basic and Frontier Research Project of CQ (cstc2014yykfC80001, cstc2015 jcyjA80007 and cstc2017jcyjAX0347), the Science and Technology Research Project of the Chongqing Education Committee (KJ1400506) and the Foundation Project of Chongqing Normal University (14XLB001). We affirm that the experiments comply with the existing laws in the country where the experiments were performed.

\section{LITERATURE CITED}

Bagatto B, Pelster B, Burggren WW (2001) Growth and metabolism of larval zebrafish: effects of swim training. J Exp Biol 204:4335-4343

Blake RW (2004) Fish functional design and swimming performance. J Fish Biol 65:1193-1222

Brett JR (1964) The respiratory metabolism and swimming performance of young sockeye salmon. J Fish Res Board Can 21:1183-1226

Cai L, Chen L, Johnson D, Gao Y and others (2014) Integrating water flow, locomotor performance and respiration of Chinese sturgeon during multiple fatigue-recovery cycles. PLOS ONE 9:e94345

Castro V, Grisdale-Helland B, Helland SJ, Kristensen T and others (2011) Aerobic training stimulates growth and promotes disease resistance in Atlantic salmon (Salmo salar). Comp Biochem Physiol A 160:278-290

Claireaux G, Couturier C, Groison AL (2006) Effect of temperature on maximum swimming speed and cost of transport in juvenile European sea bass (Dicentrarchus labrax). J Exp Biol 209:3420-3428

Colavecchia M, Katopodis C, Goosney R, Scruton DA, McKinley RS (1998) Measurement of burst swimming performance in wild Atlantic salmon (Salmo salar L.) using digital telemetry. Regul Rivers Res Manage 14: 41-51

* Davie PS, Wells RMG, Tetens V (1986) Effects of sustained swimming on rainbow trout muscle structure, blood oxygen transport, and lactate dehydrogenase isozymes: evidence for increased aerobic capacity of white muscle. J Exp Zool 237:159-171

Davison W (1997) The effects of exercise training on teleost fish, a review of recent literature. Comp Biochem Physiol A 117:67-75

Davison W, Goldspink G (1977) The effect of prolonged exercise on the lateral musculature of the brown trout (Salmo trutta). J Exp Biol 70:1-12

* Davison W, Goldspink G (1978) The effect of training on the swimming muscles of the goldfish (Carassius auratus). J Exp Biol 74:115-122

Duan XB, Chen DQ, Liu SP, Chi CG, Yang RH (2002) Studies on status of fishery resources in Three Gorges reservoir reaches of the Yangtze River. Shui Sheng Sheng Wu Hsueh Bao 26:605-611

Farrell AP, Johansen JA, Suarez RK (1991) Effects of exercise-training on cardiac performance and muscle enzymes in rainbow trout, Oncorhynchus mykiss. Fish Physiol Biochem 9:303-312

Fu SJ (2015) Flow and stress acclimation both enhance predator avoidance in a common cyprinid fish. Aquat Biol 24: $1-8$

* Fu SJ, Brauner CJ, Cao ZD, Richards JG, Peng JL, Dhillon R, Wang YX (2011) The effect of acclimation to hypoxia and sustained exercise on subsequent hypoxia tolerance and swimming performance in goldfish (Carassius auratus). J Exp Biol 214:2080-2088

Gallaugher PE, Thorarensen H, Kiessling A, Farrell AP (2001) Effects of high intensity exercise training on cardiovascular function, oxygen uptake, internal oxygen transport and osmotic balance in chinook salmon (OnCorhynchus tshawytscha) during critical speed swimming. J Exp Biol 204:2861-2872

* Gao X, Zeng Y, Wang J, Liu H (2010) Immediate impacts of the second impoundment on fish communities in the 
Three Gorges Reservoir. Environ Biol Fishes 87:163-173

Graham JB, Dewar H, Lai NC, Lowell WR, Arce SM (2004) Aspects of shark swimming performance determined using a large water tunnel. J Exp Biol 151:175-192

Gregory TR, Wood CM (1998) Individual variation and interrelationships between swimming performance, growth rate, and feeding in juvenile rainbow trout (Oncorhynchus mykiss). Can J Fish Aquat Sci 55:1583-1590

* Gruber SJ, Dickson KA (1997) Effects of endurance training in the leopard shark, Triakis semifasciata. Physiol Zool 70:481-492

$\mathrm{He}$ W, Xia W, Cao ZD, Fu SJ (2013) The effect of prolonged exercise training on swimming performance and the underlying biochemical mechanisms in juvenile common carp (Cyprinus carpio). Comp Biochem Physiol A 166: 308-315

Hoffnagle TL, Carmichael RW, Keniry PJ (2006) The effect of moderately increased and variable raceway flow rates on juvenile physiology, survival, and adult return of hatchery-reared Chinook Salmon. Trans Am Fish Soc 135:1567-1577

* Ibarz A, Felip O, Fernández-Borràs J, Martín-Pérez M, Blasco J, Torrell JR (2011) Sustained swimming improves muscle growth and cellularity in gilthead sea bream. J Comp Physiol B 181:209-217

Jobling M, Baardvik BM, Christiansen JS, Jørgensen EH (1993) The effects of prolonged exercise training on growth performance and production parameters in fish. Aquacult Int 1:95-111

Johnston IA, Moon TW (1980) Endurance exercise training in the fast and slow muscles of a teleost fish (Pollachius virens). J Comp Physiol 135:147-156

Kieffer JD (2010) Perspective-exercise in fish: 50+ years and going strong. Comp Biochem Physiol A 156:163-168

* Lee CG, Farrell AP, Lotto A, Hinch GS, Healey MC (2003a) Excess post-exercise oxygen consumption in adult sockeye (Oncorhynchus nerka) and coho (O. kisutch) salmon following critical speed swimming. J Exp Biol 206: 3253-3260

Lee CG, Farrell AP, Lotto A, MacNutt MJ, Hinch SG, Healey MC (2003b) The effect of temperature on swimming performance and oxygen consumption in adult sockeye (Oncorhynchus nerka) and coho (O. kisutch) salmon stocks. J Exp Biol 206:3239-3251

Li WJ, Wang JW, Xie CX, Tan DQ (2007) Reproductive biology and spawning habitats of Megalobrama pellegrini, an endemic fish in upper-reaches of Yangtze River basin. Acta Ecol Sin 27:1917-1925

Li XM, Cao ZD, Peng JL, Fu SJ (2010a) The effect of exercise training on the interaction of feeding and exercise in juvenile southern catfish (Silurus meridionalis Chen). J Exp Zool A 313A:557-563

Li XM, Cao ZD, Peng JL, Fu SJ (2010b) The effect of exercise training on the metabolic interaction between digestion and locomotion in juvenile darkbarbel catfish (Peltebagrus vachelli). Comp Biochem Physiol A 156:67-73

Li XM, Yu LJ, Wang C, Zeng LQ, Cao ZD, Fu SJ, Zhang YG (2013) The effect of aerobic exercise training on growth performance, digestive enzyme activities and postprandial metabolic response in juvenile qingbo (Spinibarbus sinensis). Comp Biochem Physiol A 166:8-16

Li XM, Liu L, Yuan JM, Xiao YY, Fu SJ, Zhang YG (2016) The effect of aerobic exercise and starvation on growth performance and postprandial metabolic response in juvenile southern catfish (Silurus meridionalis). Comp
Biochem Physiol A 193:36-44

Liu Y, Cao ZD, Fu SJ, Peng JL, Wang YX (2009) The effect of exhaustive chasing training and detraining on swimming performance in juvenile darkbarbel catfish (Peltebagrus vachelli). J Comp Physiol B 179:847-855

*Martin CI, Johnston IA (2005) The role of myostatin and the calcineurin-signalling pathway in regulating muscle mass in response to exercise training in the rainbow trout Oncorhynchus mykiss Walbaum. J Exp Biol 208:2083-2090

* Martin CI, Johnston IA (2006) Endurance exercise training in common carp Cyprinus carpio L. induces proliferation of myonuclei in fast muscle fibres and slow muscle fibre hypertrophy. J Fish Biol 69:1221-1227

Nelson JA, Tang Y, Boutilier RG (1996) The effects of salinity change on the exercise performance of two Atlantic cod (Gadus morhua) populations inhabiting different environments. J Exp Biol 199:1295-1309

*Palstra AP, Planas JV (2011) Fish under exercise. Fish Physiol Biochem 37:259-272

* Pang X, Cao ZD, Fu SJ (2011) The effects of temperature on metabolic interaction between digestion and locomotion in juveniles of three cyprinid fish (Carassius auratus, Cyprinus carpio and Spinibarbus sinensis). Comp Biochem Physiol A 159:253-260

*Pang X, Yuan XZ, Cao ZD, Fu SJ (2013) The effects of temperature and exercise training on swimming performance in juvenile qingbo (Spinibarbus sinensis). J Comp Physiol B 183:99-108

* Park YS, Chang JB, Lek S, Cao WX, Brosse S (2003) Conservation strategies for endemic fish species threatened by the Three Gorges Dam. Conserv Biol 17:1748-1758

Pearson MP, Spriet LL, Stevens ED (1990) Effect of sprint training on swim performance and white muscle metabolism during exercise and recovery in rainbow trout (Salmo gairdneri). J Exp Biol 149:45-60

*Peng J, Cao ZD, Fu SJ (2014) Effects of temperature and digestion on the swimming performance of juvenile Chinese bream. Aquat Biol 21:183-189

*Plaut I (2001) Critical swimming speed: its ecological relevance. Comp Biochem Physiol A 131:41-50

Priede IG (1985) Metabolic scope in fishes. In: Tytler P, Calow P (eds) Fish energetics. Croom-Helm, London, p 33-64

Rasmussen RS, Heinrich MT, Hyldig G, Jacobsen C, Jokumsen A (2011) Moderate exercise of rainbow trout induces only minor differences in fatty acid profile, texture, white muscle fibres and proximate chemical composition of fillets. Aquaculture 314:159-164

Song BL, Lin XT, Xu ZN (2012) Effects of upstream exercise training on feeding efficiency, growth and nutritional components of juvenile tinfoil barbs (Barbodes schwanenfeldi). Shuichan Xuebao 36:106-114

* Totland GK, Kryvi H, Jødestøl KA, Christiansen EN, Tangerås A, Slinde E (1987) Growth and composition of the swimming muscle of adult Atlantic salmon (Salmo salar L.) during long-term swimming. Aquaculture 66: 299-313

*van der Meulen T, Schipper H, van den Boogaart JGM, Huising MO, Kranenbarg S, van Leeuwen JL (2006) Endurance exercise differentially stimulates heart and axial muscle development in zebrafish (Danio rerio). Am J Physiol Regul Integr Comp Physiol 291: R1040-R1048

Wang JW, Tan DQ, Li WJ (2005) Preliminary studies on artificial propagation and embryonic development of Mega- 
lobrama pellegrini. Shui Sheng Sheng Wu Hsueh Bao 29:130-136

Webb PW (1975) Hydrodynamics and energetics of fish propulsion. Bull Fish Res Board Can 199:109-119

Young PS, Cech JJ (1993) Improved growth, swimming performance, and muscular development in exercisedconditioned young-of-the-year striped bass (Morone saxatilis). Can J Fish Aquat Sci 50:703-707

Editorial responsibility: Helmut Segner,

Bern, Switzerland
Zhao WW, Pang X, Peng JL, Cao ZD, Fu SJ (2012) The effects of hypoxia acclimation, exercise training and fasting on swimming performance in juvenile qingbo (Spinibarbus sinensis). Fish Physiol Biochem 38:1367-1377

Zhu YP, Cao ZD, Fu SJ (2010) Aerobic and anaerobic metabolism in response to different swimming speed of juvenile darkbarbel catfish (Pelteobagrus vachelli Richardson). Shui Sheng Sheng Wu Hsueh Bao 34:905-912

Submitted: September 21, 2016; Accepted: June 27, 2017 Proofs received from author(s): August 23, 2017 